\title{
Socio-economic Variable of Parents as a Correlate Promoting Teenage Pregnancy Among Medical Students in Delta State University, Abraka
}

Bartholomew Chukwuebuka Nwogueze ( $\sim$ bukasono123@gmail.com )

Bingham University Teaching Hospital

\section{Simon Irikefe Ovuakporaye}

Delta State University Abraka

Tarela Elias M Daubry

Delta State University Abraka

Tochukwu Nnamdi Nnama

Evangel University Akaeze

\section{Richard Nduka Ossai}

Delta State University Abraka

Jane-Francis Onyinye Nwogueze

Delta State University Abraka

Research article

Keywords: Parents, Teenage pregnancy, Socio-economic variable, Medical students

Posted Date: July 30th, 2020

DOl: https://doi.org/10.21203/rs.3.rs-46789/v1

License: (9) (i) This work is licensed under a Creative Commons Attribution 4.0 International License. Read Full License 


\section{Abstract}

Purpose: The incidence of teenage pregnancy has attracted global concern due to its impact on the teen's maternal health, the overall wellbeing of the child and the society at large. This study examined socioeconomic variable of parents as a correlate promoting teenage pregnancy among medical students in Delta State University, Abraka Delta State.

Methods: The Ex-Post Facto method was chosen as the research design for the study. 294 female medical students were selected from a total of 982 students from the medical college using simple random sampling technique. The instruments used for data collection was a self-structured and welldesigned questionnaire containing 25 multiple choice items based on the research questions developed in the study. 278 questionnaires were successful retrieved from the field and was used for data analysis. Frequency count, percentages, mean score and Pearson product moment correlation were employed as the statistical technique for data analysis. SPSS version 21.0 was utilized for data analysis.

Results: Findings from this study revealed that parental income $(p=0.003)$ and occupation $(p=0.005)$ were the viable parents' socio-economic variable promoting teenage pregnancy among medical students in Delta State University, Abraka when compared to educational background $(p=0.343)$, religion $(p=0.307)$ and marital status $(p=0.053)$ variables that were not significantly related.

Conclusions: It appears that significant number of adolescent female students who become pregnant has to leave school and this have a long-term implication for them as individual, their family and their community. Therefore, effective parent-daughter relationships and school-based reproductive health education programmes are strongly recommended.

\section{Introduction}

Teenage is a time of obvious physical changes. The concept "teenage pregnancy" may vary from one individual to the next relying upon the perspective one ganders at it. Teenage pregnancy is a situation in which a girl in her teenage years (13-19) becomes a mother as a result of getting pregnant. Pregnancy among many adolescent girls can result to devastating health complications [1, 2]. It is a biology process whereby the sperm fertilizes the ovum released by the ovary and the fertilized ovum travels down the fallopian tube were it attaches to the uterus to form the embryo and the placenta [3]. Pregnancy usually occurs by sexual intercourse and/or by Assisted Reproductive Technology [4]. Childbirth around pregnancy typically takes place within 40 weeks from the time of last menstrual period (LMP). According to Eunice, [3] pregnancy can be generally classified into three periods of trimesters, namely; the first trimester, second trimester and third trimester respectively.

Pregnancy among teenagers is increasing despite its increasing threat to schooling with several health implications especially among those in tertiary institutions $[5,6,7]$. World Health Organization (WHO), [8] 
reported that most adolescent girls between the age of 15 to 19 get pregnant and that globally close to 16 million of these women give birth yearly resulting to about $11 \%$ of all births. In Nigeria, teenage pregnancy is seen as a serious problem as an estimated $23 \%$ of women between 15-19 years have begun childbearing, out of which $17 \%$ have had their first child and $5 \%$ are pregnant with their first child $[9,10,11]$. Teenage pregnancy is condition that has often been linked with in negative consequences on the adolescents and their children. Finer and Zolna, [12] maintains that an approximate of $26 \%$ of teenage pregnancies end in abortion. The report of UNFPA, [13] have identified the following as the underlying cause of teenage pregnancy include; parents' socio-economic status, gender inequality, child marriage, poverty, sexual violence, obstacles to human rights, national policies restricting access to contraception, age, lack of access to education.

Parents' socio-economic status has impact on the rate of teenage pregnancies in different countries of the world [11]. In Nigeria and other developing countries, parent's socio-economic status such as; parental income, education level, parental occupation, family size, income level and family structure of the learner could influence the rate of teenage pregnancy $[14,15]$. More often, these girl child drops out of school mostly due to pressures they experience such as; shame, stigmatization and disgrace that is limited with early parenting; they begin confining from their companions with absence of the vital help from their friends, family, schools and different organizations. At the long run, this could eventually terminate their dreams of achieving higher pursuits. Hence, the need for this study to explore parent's socio-economic variable as a correlate of teenage pregnancy among medical students in Delta State University, Abraka.

\section{Materials \& Methods}

\section{Research Design}

The Ex-Post Facto was utilized as the research design for the study. The choice of the design is because it attempts to investigate parents' socio-economic variables such as; income, education level, occupation religion and marital status as a correlate promoting teenage pregnancy among medical students in Delta State University, Abraka. According to Igwebuike, [16] using Ex-Post Facto research design allows the researcher not to manipulate or control the variables and perhaps, the cause-effect relationship established are tentative in nature.

\section{Sample size and Sampling}

Data used in the present study were obtained from a total of 982 female medical students aged 1525years. 294 female students were sampled from four Departments from the College of Health Sciences. A simple random sampling through balloting was used for selecting three (3) Departments from the Faculty of Basic Medical Science in the university.

\section{Research Instruments}


The instrument used for data collection was s well-structured questionnaire titled 'Parents Socioeconomic Variables and Teenage Pregnancy Survey (PSVTPS)' developed by the researcher after extensive review of literature. The questionnaire method according to Mugenda and Mugenda, [17] was chosen because it was considered easy to manage and could help the researcher to concurrently gather elicit information from the participants therefore saving time. Orodho, [18] opined that a questionnaire allows dimension for or beside a particular viewpoint and that questionnaire has the capability to gather a great amount of information in a reasonably short time. The instrument employed the 4-Likert scale points ranging from strongly agree (SA)-4, agree (A)-3, disagree (D)-2 to strongly disagree (SD)-1.

\section{Ethical Clearance}

Prior to the study, ethical clearance was obtained from the Bioethics Committee on Research of the Faculty of Basic Medical Sciences, Delta State University, Abraka. Oral and written permissions from the Dean of the Faculty and the respective study subjects were equally obtained before the time of data collection.

\section{Method of Data Collection}

Before visiting the identified sampled respondents, the researcher sorted permission from the relevant authorities within the Medical College. The researcher thereafter administered the questionnaire personally to the participants to enhance large returns. 278 questionnaires were successfully filled and retrieved from the students. Their responses were scored and the data generated were collated for statistical analysis.

\section{Statistically Analysis}

The completed questionnaires were collated, coded and analyzed using both descriptive and inferential statistics. For the descriptive statistics, frequency counts, percentages, bar and pie charts were used to illustrate the section. The average mean for the research items generated with a score of 2.50 and above indicating agreement benchmark while scores below 2.50 were not considered. For the inferential statistics, Pearson Product Moment Correlation (PPMC) coefficient was employed. Statistical Package for Social Sciences (SPSS) version 22.0 was utilized for data analysis.

\section{Results}

\section{Demographic Data of Respondents}

Figure 1 below revealed that a total of $88(31.6 \%)$ of the participants for the study were medical students in Physiology Department, 80(28.8\%) were students from Anatomy Department, 65(23.38\%) were 
students in Nursing science and the remaining 45(16.19\%) were students in medicine and surgery. Based on the academic levels of the students, 121(43.53\%) were in 200level, 102(36.69\%) were in 300level and the remaining 55(19.8\%) were 400level students respectively. This showed that a very high percentage of the responses were gathered from college students in 200 level.

Figure 2 below showed that 135(48\%) out of the 278 sampled students falls within the age bracket of 2225yrs. $80(29 \%)$ of the students are aged 18-22years, while the remaining $64(23 \%)$ are between the age range of 15-18 years. This showed that a high percentage of the respondents are still in their active reproductive age

Figure 3 below showed that 237(85.3\%) of the respondents are Christians, 12(4.3\%) persons were Muslim while the remaining $29(10.4 \%)$ of them belonged to the Traditional Religion. Could their religion have influence on the level of teenage pregnancy among medical student?

\section{Inferential Statistics: Answering Of Research Questions}

Table 1 below depicts a picture of the responses on relationship between parental income and teenage pregnancy. Out of the 5 items tested, it was revealed that all were accepted. Hence, items 1, 2, 3, 4 and 5 respectively had a mean score above the bench mark of 2.50 and were adopted. This implies that teenage pregnancy is common among students whose parents earn low incomes or from poorer homes. Consequently, teenage pregnancy certainly affects students whose parents are struggling to support their medical education. In addition, consequences of teenage pregnancies are enormous among students whose parents have no employment and this often results to dropout of students from medical school. Based on hypothesis I formulated, it was observed that the parental income variable had a higher mean score of 110.3 with a standard deviation of 32.6 when compared to the teenage pregnancy variable that had a mean score of 28.8 with a standard deviation of 27.8. Hence, the result indicates that the rcalculated value of 0.828 is greater than the r-critical value of 0.440 at $p<0.05$ levels of significance. Hence, the null hypothesis I is rejected. Therefore, we conclude that there is significant relationship between parental income and teenage pregnancy among medical students in College of Health Sciences, Delta State University, Abraka. 
Table 1

Relationship between Parental Income and Teenage Pregnancy

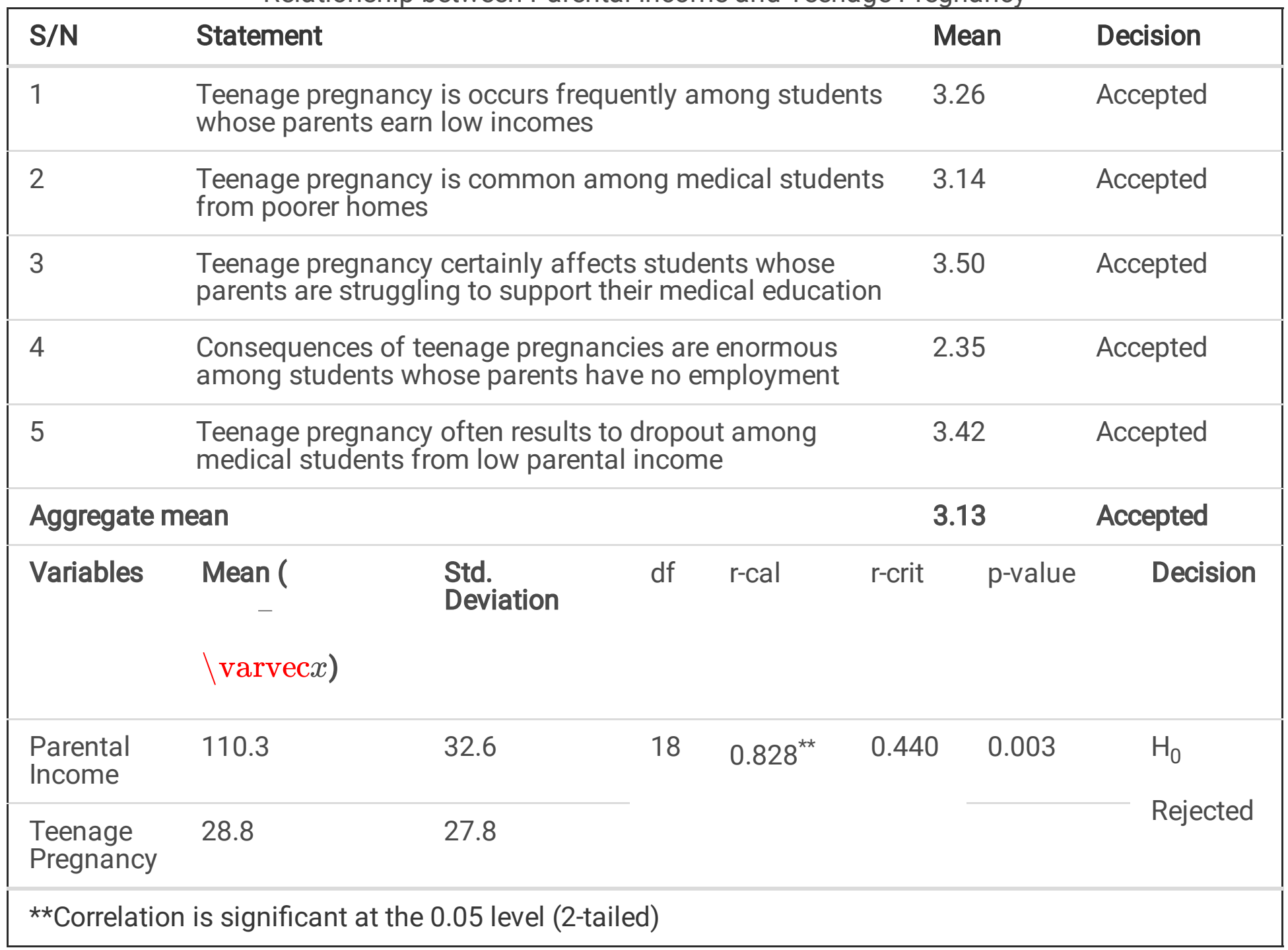

The data analyzed in Table 2 below represents the relationship between education level of parents and teenage pregnancy among medical students. Five (5) items were used to analyze the statement, whereas, the result obtained clearly revealed that all the items tested were accepted. Hence, item 6-10 respectively had a mean score above 2.50 , thus, were adopted. This implies that parents' educational achievements has less impact on the incidence of teenage pregnancy, uneducated parents do not readily advice their children of the risk factor of teenage pregnancy; hence, teenage pregnancy is common among parents with no formal education. Meanwhile parents with formal education help teenagers to execute and coordinate their experience as well as helps students to be conscious of the risk associated with teenage pregnancy. It was equally observed that the r-cal value of 0.336 for the Pearson Product Moment Correlation analysis for Hypothesis II was less than the r-crit value of 0.440 at $p>0.05$ levels of significance. Meanwhile, the education level of parent's variable had a mean score of 118.4 with a standard deviation of 20.6 greater than the teenage pregnancy variable that had a mean score of 43.8 with a standard deviation of 13.8. Since, the r-critical value was greater than the r-calculated value, hence, the null hypothesis II formulated is accepted. This implies that there is no significant relationship between 
education level of parents and teenage pregnancy among medical students in College of Health Sciences, Delta State University, Abraka.

Table 2

Relationship between Education Level of Parents and Teenage Pregnancy

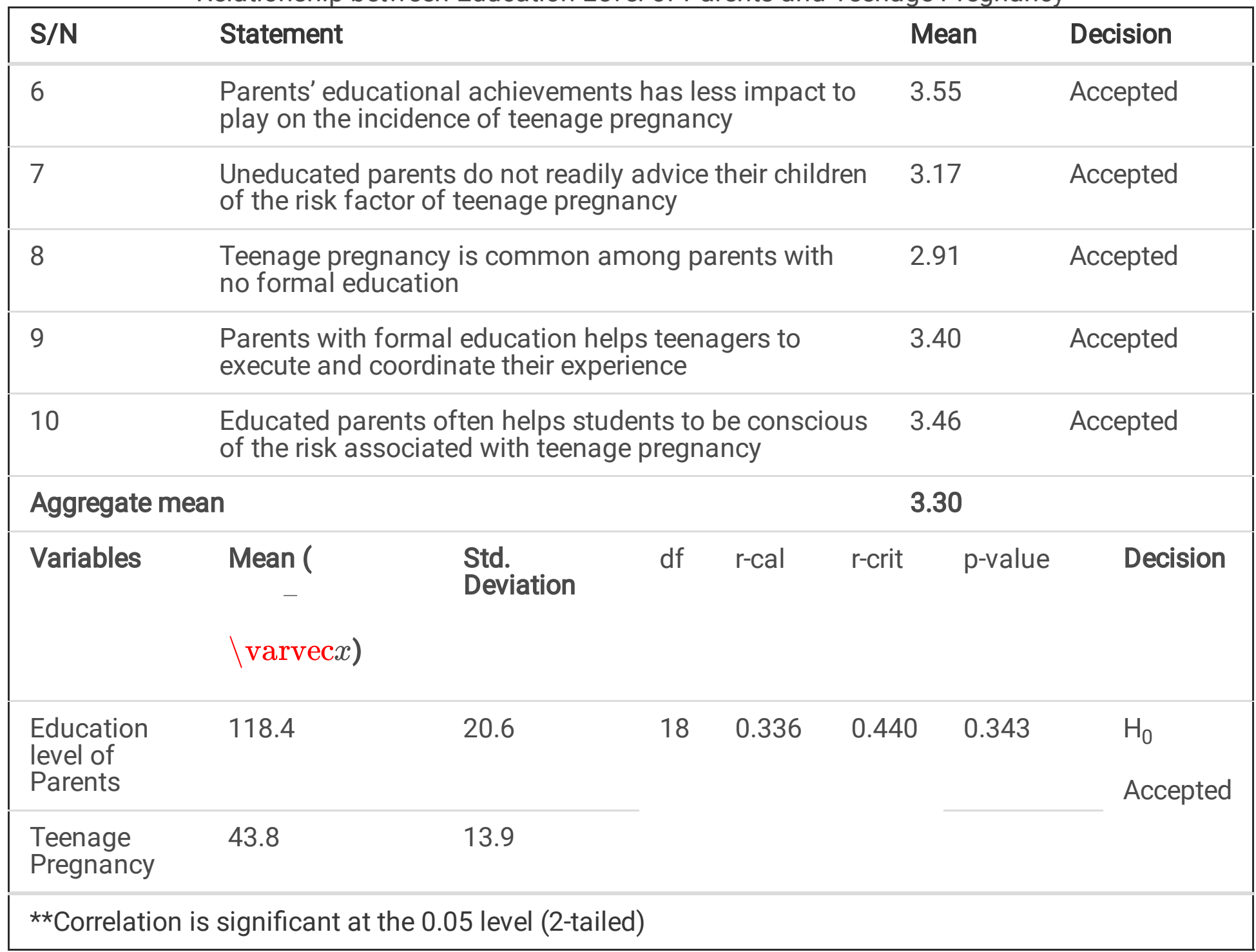

Table 3 below shows the responses on relationship between parental occupation and teenage pregnancy among medical students. It was gathered that 3 items out of the 5 generated statements were accepted, which implies that item 11, 12 and 13 respectively had a mean score above the bench mark of 2.50 and were adopted, while item 14 and 15 had a mean score below 2.50 and was rejected. This implies that occupation of parents determines the incidence of teenage pregnancy and this affects student's attitude towards teenage pregnancy, also, parents' occupation status influences the knowledge of students towards consequences of teenage pregnancy. Result obtained with regards to Hypothesis III revealed that parental occupation variable had a higher mean score of 89.6 with a standard deviation of 55.9 when compared to the teenage pregnancy variable that had a mean score of 49.4 with a standard deviation of 23.9. Considering that the r-calculated value of 0.805 was greater than the r-critical value of 0.440 at $p<$ 0.05 levels of significance, therefore, we conclude that there is significant relationship between parental 
occupation and teenage pregnancy among medical students in College of Health Sciences, Delta State University, Abraka.

Table 3

Relationship between Parental Occupation and Teenage Pregnancy

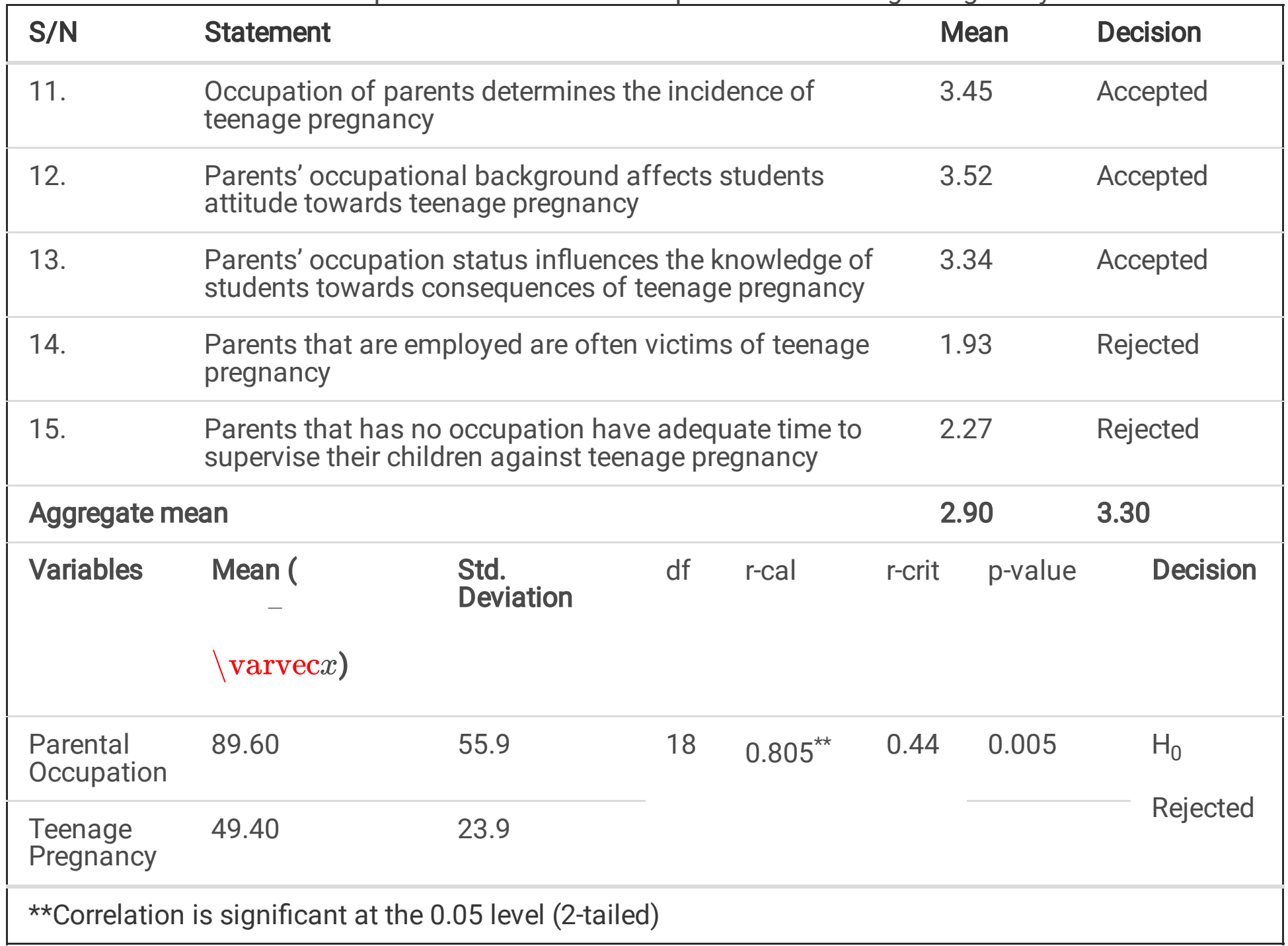

Table 4 below represents the statement on the relationship between parents' religion and teenage pregnancy among medical students. It was obtained from the analysis that all the items generated, that is, $16,17,18,19$ and 20 respectively had a mean score above 2.50 and were accepted. Hence, this implies that students whose parents has value for religion are not victims of teenage pregnancy, religion is a powerful social force and provides a moral framework for socialization, in addition, students whose parents often conduct morning devotions are less likely to experience teenage pregnancy, also, students whose parents fails to have their marriage blessed in the church are likely to experience teenage pregnancy and students whose parents had mixed marriage are likely to experience teenage pregnancy. Considering Hypothesis IV; it was revealed that the r-cal value of 0.360 is less than the r-crit value of 0.440 at $P>0.05$ levels of significance. Result obtained shows that parent's religion variable had a higher mean score of 115.20 with a standard deviation of 31.5 when compared to the teenage pregnancy variable that had a mean score of 23.80 with a standard deviation of 21.3. Hence, the null hypothesis of 
is accepted. Therefore we conclude that there is no significant relationship between parents' religion and teenage pregnancy among medical students in College of Health Sciences, Delta State University, Abraka.

Table 4

Relationship between Parent's Religion and Teenage Pregnancy

\begin{tabular}{|c|c|c|c|c|c|c|c|}
\hline$S / N$ & \multicolumn{5}{|c|}{ Statement } & Mean & Decision \\
\hline 16. & \multicolumn{5}{|c|}{$\begin{array}{l}\text { Students whose parents has value for religion are not } \\
\text { victims of teenage pregnancy }\end{array}$} & 2.94 & Accepted \\
\hline 17. & \multicolumn{5}{|c|}{$\begin{array}{l}\text { Religion is a powerful social force and provides a moral } \\
\text { framework for socialization }\end{array}$} & 3.49 & Accepted \\
\hline 18. & \multicolumn{5}{|c|}{$\begin{array}{l}\text { Students whose parents often conduct morning devotion } \\
\text { are less likely to experience teenage pregnancy }\end{array}$} & 3.43 & Accepted \\
\hline 19. & \multicolumn{5}{|c|}{$\begin{array}{l}\text { Students whose parents fails to have their marriage } \\
\text { blessed in the church are likely to experience teenage } \\
\text { pregnancy }\end{array}$} & 2.94 & Accepted \\
\hline 20. & \multicolumn{5}{|c|}{$\begin{array}{l}\text { Students whose parents had mixed marriage are likely to } \\
\text { experience teenage pregnancy }\end{array}$} & 3.51 & Accepted \\
\hline \multicolumn{6}{|c|}{ Aggregate mean } & \multicolumn{2}{|c|}{3.26} \\
\hline Variables & $\begin{array}{c}\text { Mean ( } \\
\quad- \\
\text { \varve }\end{array}$ & Std. Deviation & $\mathrm{df}$ & r-cal & r-crit & p-value & Decision \\
\hline $\begin{array}{l}\text { Parents' } \\
\text { Religion }\end{array}$ & 115.20 & 31.5 & \multirow[t]{2}{*}{18} & \multirow[t]{2}{*}{0.360} & \multirow[t]{2}{*}{0.440} & 0.307 & \multirow{2}{*}{$\begin{array}{l}\mathrm{H}_{0} \\
\text { Accepted }\end{array}$} \\
\hline $\begin{array}{l}\text { Teenage } \\
\text { Pregnancy }\end{array}$ & 23.80 & 21.3 & & & & & \\
\hline **Correlatio & signifi & 05 level (2-tai & & & & & \\
\hline
\end{tabular}

Table 5 below represents statements on the relationship between parents' marital status and teenage pregnancy among medical students. Out of the 5 items generated, 3 of the items, that is, 21, 22 and 25 had a mean score above the bench mark of 2.50 and were accepted while the remaining 2 items; 23 and 24 respectively had a mean score below 2.50 and were rejected. This implies that students from broken homes and polygamous family are likely to engage in teenage pregnancy. Thus, poor parental supervision as a result of broken homes promotes likelihood of teenage pregnancy. The r-cal value of 0.626 for the Pearson Product Moment Correlation analysis for Hypothesis $V$ was less than the $r$-crit value of 0.440 at $p<0.05$ levels of significance. Meanwhile, the parent's marital status variable had a higher mean score of 77.20 with a standard deviation of 50.9 greater than the teenage pregnancy variable that had a mean score of 61.8 with a standard deviation of 41.2 . Since, the r-calculated value was greater than the r-critical value, hence, the null hypothesis $V$ formulated is accepted. This implies that 
there is no significant relationship between parent's marital status and teenage pregnancy among medical students in College of Health Sciences, Delta State University, Abraka.

Table 5

Relationship between Parent's Marital Status and Teenage Pregnancy

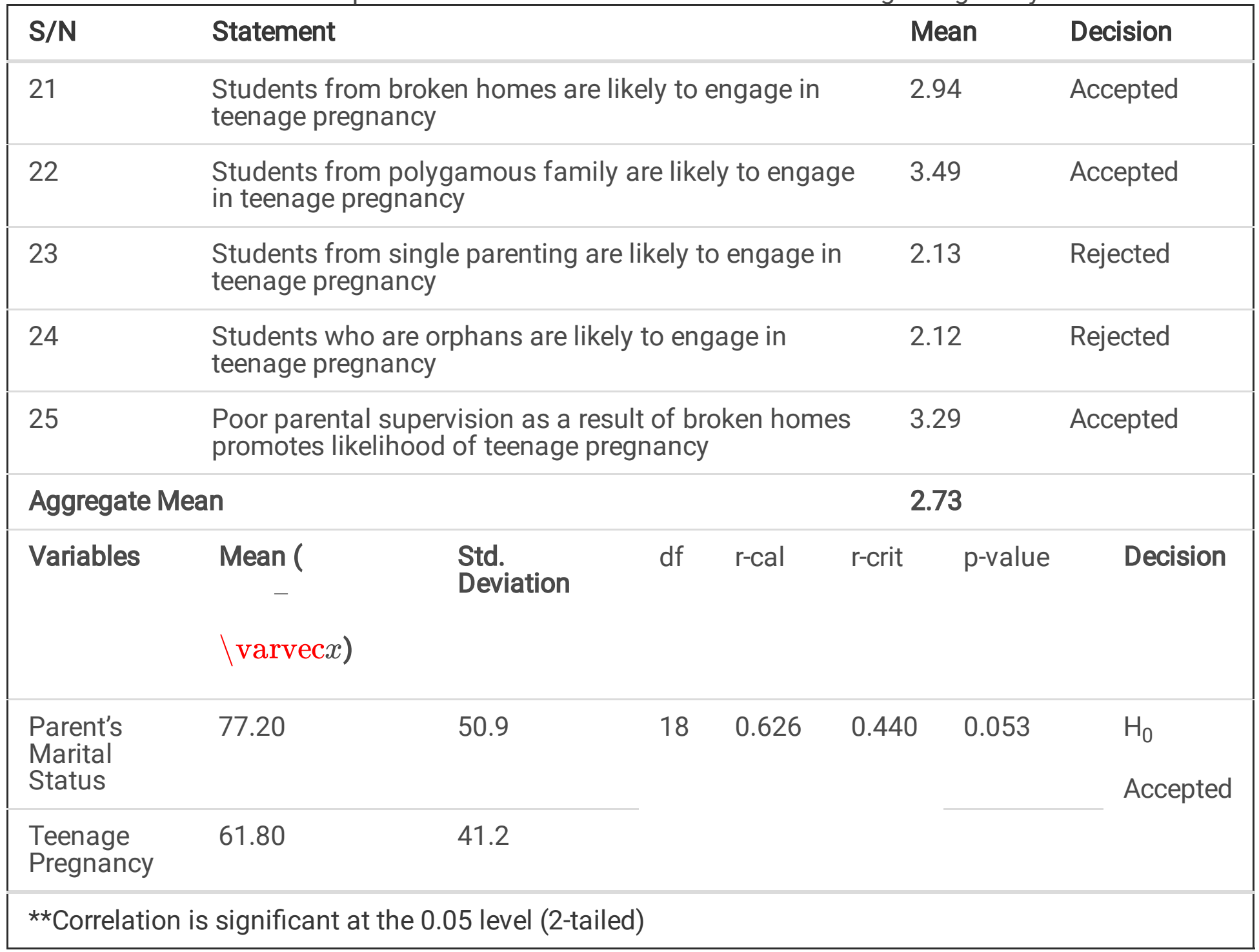

\section{Discussion}

Teenage pregnancy is one of the most usually unplanned and unfavourable outcomes of adolescents' sexual activity which constitutes a public health problem to teenagers, families and the society at large. Findings from this present study have revealed that teenage pregnancy is common among students from low parental income and/or poorer homes, and thus, certainly affect students whose parents are struggling to support their medical education and parents that have no employment thus resulting to frequent dropouts. The outcome of this study corroborates the findings of Bello, [19] who found that children from high socio economic background have a better chance of succeeding in school than their low socio economic status counterparts; however, this determines the attitude of the student to teenage pregnancy. Also, it agrees with the opinion of Odukwe, [20] who confirmed that children from high 
economic background are able to enroll in lesson, buy necessary text books and stationary when compared to those students from poorer homes.

Parental education was not found to have significant relationship with teenage pregnancy among medical students, as such; parent's educational achievement has less impact to play on the incidence of teenage pregnancy. Although, uneducated parents do not readily advice their children of the risk factor of teenage pregnancy; hence, making teenage pregnancy a common phenomenon among parents with no formal education when compared to parents with formal education who are readily knowledgeable on strategies to help teenagers to execute and coordinate their experience as well as helps students to be conscious of the risk associated with teenage pregnancy. This finding is consistent with studies conducted by $[21,22,23]$ who did not find any significant association between family educational characteristics and the experience of teenage pregnancy while on the contrary the study conducted by Naziru, [24] and Philemon, [25] found significant association.

Occupation of parents was found to determine the incidence of teenage pregnancy and this affects student's attitude towards teenage pregnancy. Furthermore, the study revealed that parents' occupation influences the knowledge of students towards consequences of teenage pregnancy. This confirmed the submission of Muraina and Ajayi, [26] that parental employment is expected to have significant effect on the welfare of their children. The author further pointed out that as far as academic performance of children is concerned, parental occupation might have both positive and negative impact on their children sexuality behavours. Similarly, Jessica and Diana, [27] in their studies reported that parental occupation can affect how parents bring their children into a culture of learning.

Religion of parents was not found to be related to teenage pregnancy. Students whose parents has value for religion are not victims of teenage pregnancy, in addition, it was believed that religion is a powerful social force which provides a moral framework for socialization, hence, parents that often conduct morning devotion are less likely to experience teenage pregnancy while, parents that fails to have their marriage blessed in the church are likely to experience teenage pregnancy as well as parents who encounter mixed marriage are likely to experience teenage pregnancy. These findings support those of Assimeng, [28] who stated that religion is a powerful social force and provides a moral framework for socialization. The findings of this study is also in line with Nalenga, [29] submission that religion is a factor linked to teenage pregnancy since religion plays a significant role in moderating sexual behaviour of adolescents, preventing prostitution and abnormal sexual practice among teen such as; homosexuality, premarital extramarital sexual intercourse and indiscriminate use of condom.

Marital status of parents was not found to be related to teenage pregnancy, although, students from broken homes and polygamous family are likely to engage in teenage pregnancy. Hence, poor parental supervision as a result of broken homes promotes likelihood of teenage pregnancy. These findings corroborate those of Meddinus and Johnson, [30] who identified poor parental supervision as a result of broken homes and inadequate or absence of contraceptives responsible for the occurrence of teenage pregnancy. On the contrary, studies by Mathewos and Mekuria, [21]; Ayele et al, [22]; Envuladu et al, [23]; 
Gideon, [31] and Alemayehu et al, [32] found significant association between marital status and teenage pregnancy.

\section{Conclusion}

Teenage pregnancy is a common a social problem which occurs globally. This study shows that there are gaps in socio-economic variable as a correlate that promotes teenage pregnancy among medical students. Several parents' socioeconomic factors have been discovered to be associated with teenage pregnancy. Result obtained from this study has shown that parental income and occupation are significantly related to occurrence of teenage pregnancy among medical students in the study area while educational background, religion and marital status are not. Therefore, it is recommended that government, religious leaders, parents and schools must as a matter urgency strengthen and reappraise their obligations towards curbing the menace of teenage pregnancies among students.

\section{List Of Abbreviations}

PSVTPS -Socio-economic Variables and Teenage Pregnancy Survey

WHO -World Health Organization

LMP - Last Menstrual Period

UNFPA -United Nation Population Fund

PPMC - Pearson Product Moment Correlation

SPSS -Statistical Package for Social Sciences

\section{Declarations}

\section{Ethics approval and consent to participate}

The investigation was approved by Research and Bio-ethics Committee of the Faculty of Basic Medical Sciences, Delta State University, Abraka.

\section{Consent for publication}

Not applicable

\section{Competing Interests}

Authors declare that they have no conflicts of interest. 


\section{Funding}

Not applicable

\section{Authors' contributions}

BC the first author and the corresponding author conceptualized the work; wrote the original draft, reviewed \& edited the paper; SI supervised the manuscript; TME and TN analyzed and interpreted the data; NR participated in distributing the questionnaires; JC searched for literatures and wrote the methodology. All authors read and approved the final manuscript.

\section{Acknowledgements}

The authors are grateful to the supervisors of this research for their time and efforts towards the completion of this manuscript.

\section{Authors' information}

BC holds' a PhD degree and is a lecturer in Human Physiology Department, and he specializes in Endocrinology and Reproduction; SI is medical doctor and associate Dean of the Faculty of Basic Medical Sciences and a lecturer in Human Physiology Department, TME is a lecturer in Human Physiology and TN holds PhD and is a lecturer in Anatomy Department.

\section{References}

1. Elendou-Enyégué PM. "Pregnancy-related dropouts and Gender Inequality in Education. " Demography. 2004;41(3):509-28.

2. Hamilton BE, Martin JA, Osterman MJK, Births. Preliminary data for 2015. Hyattsville, MD: National center for health statistics. Retrieved from https://www.cdc.gov/nchs/data/nvs r/nvsr65/nvsr65_03.pdf (2016).

3. Eunice KS. What are some common signs of pregnancy? National Institute of Child Health Human Development. 2013;2(1):1-6.

4. Shehan CL The Wiley Blackwell Encyclopedia of Family Studies. John Wiley \& Sons. (2016) p. 406.

5. Li C, Meng CX, Zhao WH, Lu HQ, Shi W, Zhang J. Risk factors for ectopic pregnancy in women with planned pregnancy: a case-control study. European Journal of Obstetrics and Gynecology and Reproductive Biology, 181(2014): 176-182.

6. Anyanwu FC, Goon DT, Tugli A. Perception on the severity of unwanted pregnancy among university students. Pak J Med Sci. 2013;29(4):923-8. 
7. Brook-Gnn J, Furstenberg FF 'Adolescent Sexual Behaviour' American Psychologist, 44(1), (2009): 149-259.

8. World Health Organization. Adolescent development. Retrieved from http://www. who.int/maternal_chil d_adolescent/topics /adolescence/dev/en/(2016).

9. Demographic Health Survey program. Teenage pregnancy in Nigeria: Facts and truth. Retrieved from dhsprogram.com/Who-We-Are/NewsRoom/Teenage-Pregnancy-in-Nigeria (2013).

10. Olukoshi AO. The Child in the Contemporary Nigeria: An Introduction to Issues. Lagos: Lamirex Printing Press; 2010.

11. Macleod C, Adolescence. Pregnancy and Abortion: Constructing a Threat of Degeneration. New York: Routledge; 2010. pp23-41.

12. Finer LB, Zolna MR. Declines in unintended pregnancy in the United States, 2008-2011. N Engl J Med. 2016;374(9):843-52.

13. UNFPA. Motherhood in childhood: Facing the challenge of adolescent pregnancy. New York, USA. (2013).

14. Ibrahim I, Owoeye G. Outcome of teenage pregnancy in the Niger Delta of Nigeria. Ethiopian Journal of Health Science. 2012;22(1):45-50.

15. Aboyeji A. Obstetric performance of teenage primigravidae. Nigeria Medical Journal. 1997;33(3):pp56-59.

16. Igwebuike TB Educational Research, Methods and Materials, Eregha (Nig.) Co., Ughelli, Delta state. (2000): pp 54-80.

17. Mugenda OMA, Mugenda AG. Research Methods: Quantitative and Qualitative Approaches. Nairobi: African Center for Technology Studies (ACTS) Press; 2003.

18. Orodho AJ. Essential of education and social sciences. Nairobi: Malisa Publishers; 2008.

19. Bello A. Determines of undergraduates Drop-out in university Business studies Department. Journal of Further Higher Education. 1999;27(2):pp123-141.

20. Odukwe O. The Ebonyi State to implement free education" Sunday punch Newspaper July 23rd (2001): p23.

21. Mathewos S, Mekuria A. Teenage pregnancy and its associated factors among school adolescents of Arba Minch town, southern Ethiopia. Ethiopian J Health Sci. 2018;28(3):pp287-98.

22. Ayele BG, Gebregzabher TG, Hailu TT, Assefa BA. Determinants of teenage pregnancy in Degua Tembien District, Tigray, northern Ethiopia: a community-based case-control study. PLoS One;. 2018;13(7):e0200898.

23. Envuladu EA, Agbo HA, Ohize VA, Zoakah Al. Determinants and outcome of teenage pregnancy in a rural community in Jos, plateau state, Nigeria. Sub-Saharan Afr J Med. 2014;1(1):p48.

24. Naziru MT. Determinants of adolescent pregnancy: a case-control study in the Amenfi West District, Ghana. (2017). 
25. Philemon MN. Factors contributing to high adolescent pregnancy rate in kinondoni municipality. Tanzania: Dar-Es-Salaam; 2007.

26. Muraina KO, Ajayi K. "Parents' Education, Occupation and Real Mother's Age as Predictors of Students' Achievement in Mathematics in Some Selected Secondary Schools in Ogun State. Nigeria" Academic Leadership: The Online Journal. 2011;9(1):38.

27. Jessica S, Diana R. The Role of Parents and Families in Teen Pregnancy Prevention: An Analysis of Programs and Policies;. J Fam Issues. 2014;35(10):pp1339-1362.

28. Assimeng M. Religion and social change in West Africa. 2nd ed. Accra: Woelipubl; 2010. Services.

29. Nalenga GZ. Causes of unintended pregnancy among adolescents in Addis Ababa, Ethiopia. Norwegian University of Life Sciences. (2012).

30. Meddinus UV, Johnson TC. Factors associated with unwanted pregnancy Retrieved from http://www.Pregnancy.org. (2007).

31. Gideon R. Factors associated with adolescent pregnancy and fertility in Uganda: analysis of the 2011 demographic and health survey data. Am J Soc Res. 2013;3(2):pp30-35.

32. Alemayehu T, Haider J, Habte D. Determinants of adolescent fertility in Ethiopia. Ethiopian J Health Dev. 2010;24(1):pp30-38.

\section{Figures}

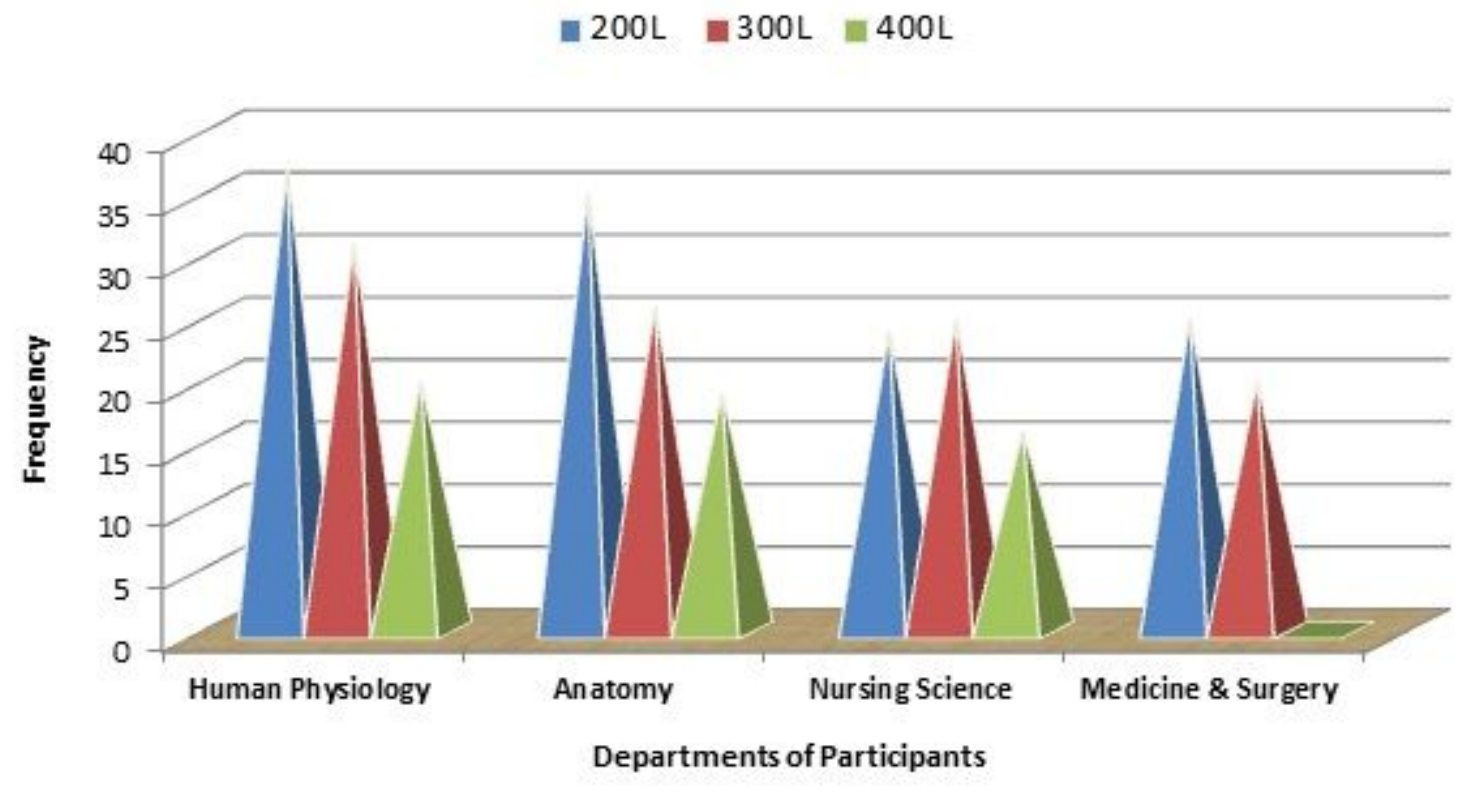

\section{Figure 1}

Frequency Distribution of Medical Students by Department and level of Study 


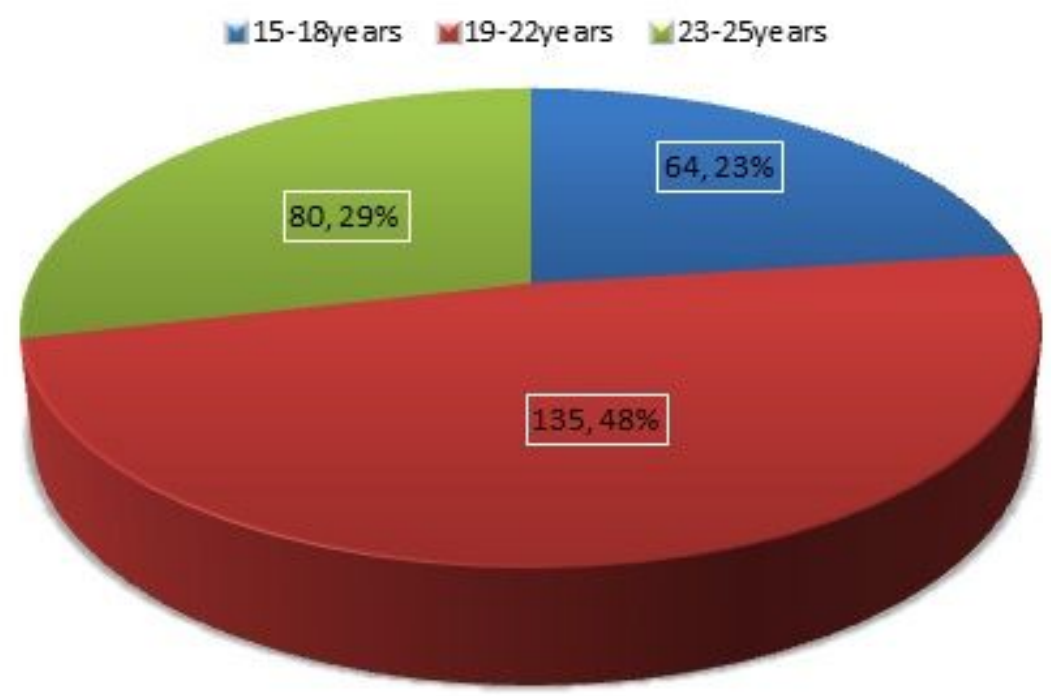

Figure 2

Pie chart showing the distribution of the Respondents by Age Distribution

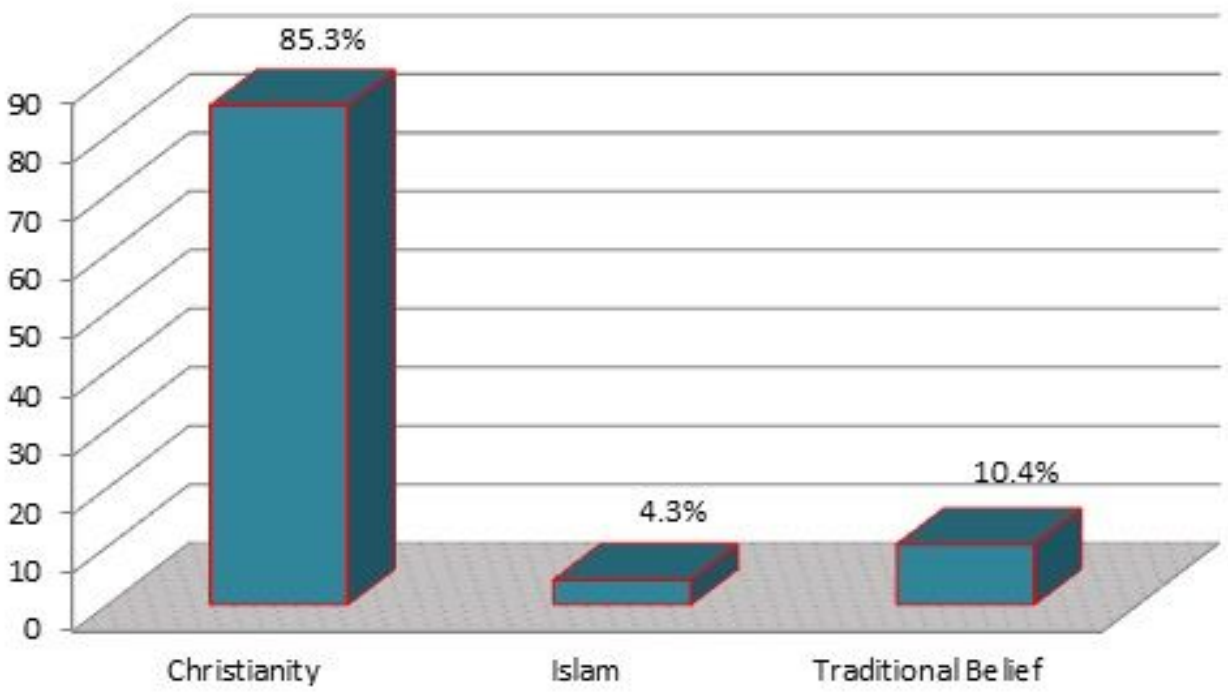

Figure 3

Bar chart showing the frequency distribution of the respondents by Religion 